\title{
Short stature and dysmorphology associated with defects in the SHOX gene
}

\author{
Sofia K. Leka, Sofia Kitsiou-Tzeli, Ariadni Kalpini-Mavrou, Emmanuel Kanavakis
}

Horemis Research Laboratory, Department of Medical Genetics, Athens University School of Medicine, "Aghia Sofia" Children's Hospital, Athens, Greece

\begin{abstract}
Since its discovery in 1997, knowledge about the SHOX gene (Short stature HOmeoboX-containing gene) has rapidly advanced. Although originally described as causing idiopathic short stature, SHOX mutations are also responsible for growth retardation in Léri-Weill dyschondrosteosis, Langer mesomelic dysplasia and Turner syndrome. Furthermore, SHOX has a broad functional scope and leads to a variety of different morphological-skeletal stigmata associated with these syndromes. This article reviews clinical and molecular data associated SHOX gene defects. Functional ongoing studies are expected to improve our understanding of the SHOX gene as comprising part of a genetic process responsible for normal growth and bone development.
\end{abstract}

Key words: LMD, LWD, Short stature, SHOX, Turner syndrome

\section{INTRODUCTION}

Linear growth is determined by environmental, hormonal and genetic factors. The multitude of growth-affecting genetic factors has recently been supplemented by the discovery in 1997 of the SHOX gene on Xpter. Rao and colleagues ${ }^{1}$ in Germany and Ellison and colleagues ${ }^{2}$ in the United States almost simultaneously reported SHOX as a candidate gene for growth failure. Previous observations had indicated that deletions of the short arm of the human

Address correspondence and requests for reprints to: Horemis Research Laboratory, Department of Medical Genetics, University of Athens, "Aghia Sofia" Children's Hospital, 11521 Goudi, Athens, Greece, Tel.: +30-210-7467464, E-mail: sleka@med.uoa.gr Received 22-12-05, Revised 20-03-06, Accepted 25-03-06
$\mathrm{X}$ and $\mathrm{Y}$ chromosomes are consistently associated with short stature..$^{3-7}$

SHOX is the abbreviated designation for the Short stature HOmeoboX-containing gene and is localized in the pseudoautosomal region of both $\mathrm{X}$ and $\mathrm{Y}$ chromosomes encoding for a transcription factor of 293 and 225 amino acids (SHOXa and SHOXb, respectively). Initial data suggested an involvement of SHOX haploinsufficiency in the etiology of idiopathic short stature (ISS; OMIM\# 604271) and the short stature in Turner syndrome (TS), ${ }^{1}$ while homozygous loss of the SHOX gene has been correlated with the Langer type mesomelic dysplasia (OMIM; 249700). ${ }^{8}$ Subsequently, heterozygous SHOX mutations were also shown to cause Léri-Weill dyschondrosteosis (LWD; OMIM \#127300). ${ }^{9}$ The overall estimate of the incidence of 
SHOX deficiency is between $1 / 2000-1 / 5000$ in the general population and 1/40-1/150 among short people. In this paper, we review the current knowledge of the SHOX gene and in particular the molecular and clinical aspects.

\section{HOMEOBOX GENES AND THE SHOX GENE}

A homeobox is a 180-base pair DNA sequence that codes for a 60 -amino acid DNA-binding region called homeodomain. A homeodomain is the DNAbinding motif of eukaryotic transcription factors, which also mediates other key functions such as nuclear localization and protein-protein interactions. Most homeobox-containing genes are involved in developmental regulation, differentiation and organogenesis and they are expressed differentially in space and time. ${ }^{10,11}$ Several hereditary disorders, such as the Waardenburg syndrome type I (PAX 3), aniridia (PAX 6) and synpolydactyly (HOXD 13), are caused by defective homeobox genes. ${ }^{12-14}$

The SHOX gene, which has been isolated by positional cloning, covers a genomic region of $40 \mathrm{~kb}$ and resides in the pseudoautosomal region (PAR1) of human sex chromosomes at Xp22 and Yp11.3, within a $170-\mathrm{kb}$ region, $500 \mathrm{~kb}$ from the telomeres. ${ }^{1}$ Because genes residing in the PAR1 region escape $\mathrm{X}$-inactivation, two copies of the SHOX gene are normally expressed in males as well as in females. The SHOX gene has one non-coding and six coding exons, ranging from 58 to $1166 \mathrm{bp}$ in size (Figure 1). The homeobox spans exons III and IV. Exons I-V

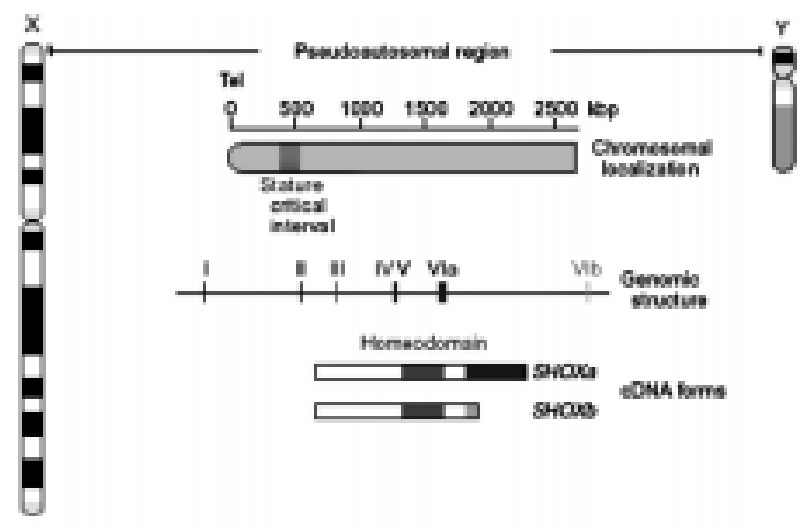

Figure 1. Chromosomal localization, genomic structures and cDNA forms of the SHOX gene. are identical in both transcripts but exon VI is presented in two forms (VIa or Vib) with different phosphorylation sites. Exon VIa, but not VIb, has a putative site for binding to $\mathrm{SH} 3$ domains that are found in cytoplasmic proteins involved in signal transduction. SHOX undergoes alternative splicing to yield two mRNAs, SHOXa (4559bp) and SHOXb (1952 bp). SHOXa and SHOXb mRNA are translated into proteins of 292 (SHOXa) and 225 (SHOXb) amino acids, respectively, that differ in the C-terminal region. ${ }^{1,2}$

The SHOX protein contains three characteristic domains: a homeodomain (a member of the $\mathrm{Q}_{50}$ paired like class), an $\mathrm{SH} 3$ binding domain and an OAR domain, and is localized at the nucleus, acting as a transcriptional regulator. Studies on the SHOX gene in human fetal tissues at six weeks of gestation have shown that it is expressed in the distal humerus, radius, ulna, wrist and first and second pharyngeal arches. Further studies have delineated that SHOXa and SHOXb are expressed in a different array of tissues. SHOXa is expressed at low levels in many tissues, while SHOXb is expressed in a more restricted manner, their highest expression level being in bone marrow fibroblasts. Neither of these two genes is expressed in the vertebrae, phalanges, heart, CNS or genitalia. ${ }^{15-17}$ Additional evidence for a role of SHOX in bone development was provided by the recent finding that the SHOX protein is detected in hypertrophic chondrocytes of the growth plate. ${ }^{17,18}$ It was also reported that SHOX expression induces cell cycle arrest and apoptosis in osteosarcoma cells as well as in primary chondrocytes, implicating a role for SHOX in the processes regulating chondrocyte differentiation. ${ }^{18}$

\section{MUTATIONS IN THE SHOX GENE}

Deletions and, less frequently, mutations of the SHOX gene have been reported in more than 200 patients to date, excluding the many patients with Turner syndrome who have a mandatory heterozygous deletion of the SHOX gene. The high frequency of repeats within the PAR1 region make this genomic region particularly prone to recombination and this is the reason why deletions are found in more than $70 \%$ of affected subjects. ${ }^{19}$ Forty-one out 
of the 59 mutations described have been detected in patients with LWD, 10 in ISS, 5 in Langer syndrome while 3 were not correlated with a specific phenotype [www.shox.uni-hd.de]. SHOX mutations were spread across the entire coding region: $21 \mathrm{mu}-$ tations were located in exon $3(44.7 \%)$, 9 mutations in exon $2(19.1 \%), 8$ in exon $4(17 \%), 5$ in exon $6 a$ (10.6\%), 3 in exon $5(6.4 \%), 1$ in intron $2(2.1 \%)$. Among them there were 44 substitutions, 9 deletions and 6 insertions (nonsense, missense or frameshift); 21 mutations concerned the homeodomain 1, 7 mutations the homeodomain 2 and 1 mutation the SH3 domain. ${ }^{1,8,9,15,20-31}$ To date, no mutation residing in the OAR domain-coding region has been found. Recent data demonstrated ${ }^{31}$ that the majority of mutant SHOX alleles in sporadic cases were transmitted from the father and this phenomenon was also observed in a previous study on SHOX mutations in patients with unexplained short stature..$^{32}$ In addition, genotyping of single human sperms has shown that the recombination fraction of the pseudoautosomal interval on the Y chromosome containing SHOX is 31 times higher than the genome's average. ${ }^{33}$ Such a high recombination fraction could explain a preferential instability of the SHOX locus during male meiosis. Most missense mutations were found to be clustered in the homeodomain. Schneider et al. ${ }^{34,35}$ have shown that a single missense mutation fundamentally impairs SHOX key functions (such as alteration of DNA binding, dimerization and nuclear translocation), thereby leading to the phenotype observed in patients with LWD and ISS. In addition, a novel class of PAR1 deletions of variable size and at least $\sim 30-530 \mathrm{~kb}$ downstream of SHOX associated with LWD has been described. ${ }^{36}$ Finally, the implication of a cisacting enhancer in the SHOX 3'region associated with skeletal phenotypes of LMD in a $45, \mathrm{X} /$ $46, X, r(X)$ infant and LWD in her 46,XX mother ${ }^{37}$ shed more light on the molecular aspects of SHOX deficiency.

\section{IMPLICATIONS OF SHOX GENE MUTATIONS}

Evidence that the SHOX gene is a critical regulator of growth was based on the following findings: 1) It is expressed during fetal life; 2) it has a highly conserved sequence in a wide variety of species; 3 ) loss or mutation of the SHOX gene is always associated with short stature; and 4) excess copies of the SHOX gene are associated with tall stature. It has been documented that SHOX functions as a repressor of growth plate fusion and skeletal maturation in the distal limbs and counteracts the skeletal maturing effects of estrogens. ${ }^{15,17}$ Consequently, SHOX's expression pattern in the ulna, radius, elbow and wrist, the equivalent bones in the leg and in the first and second pharyngeal arches explains the observed clinical features of SHOX deficiency: 1) Short stature; 2) "mesomelia", i.e. shortening of the forearms and lower legs; 3 ) cubitus valgus; 4) Madelung wrist deformity (Figure 2) i.e. bilateral shortening and bowing of the radius with a dorsal subluxation of the distal ulna, wedged carpal bones and premature fusion of the epiphysis; 5) short metacarpals/metatarsals; and 6) high-arched palate, abnormal auricular development, micrognathia and short neck. ${ }^{38}$

The clinical features of SHOX deficiency show a marked phenotypic variability, even among affected members of the same family. In general, females appear to be more severely affected than males and the skeletal defects tend to worsen with puberty. ${ }^{39,40}$ Radiographic features of SHOX deficiency are: coarse trabecular pattern, abnormal femoral neck, exostoses proximal tibial/fibula, abnormal tuberosity of humerus, radial/tibial bowing, short metacar-

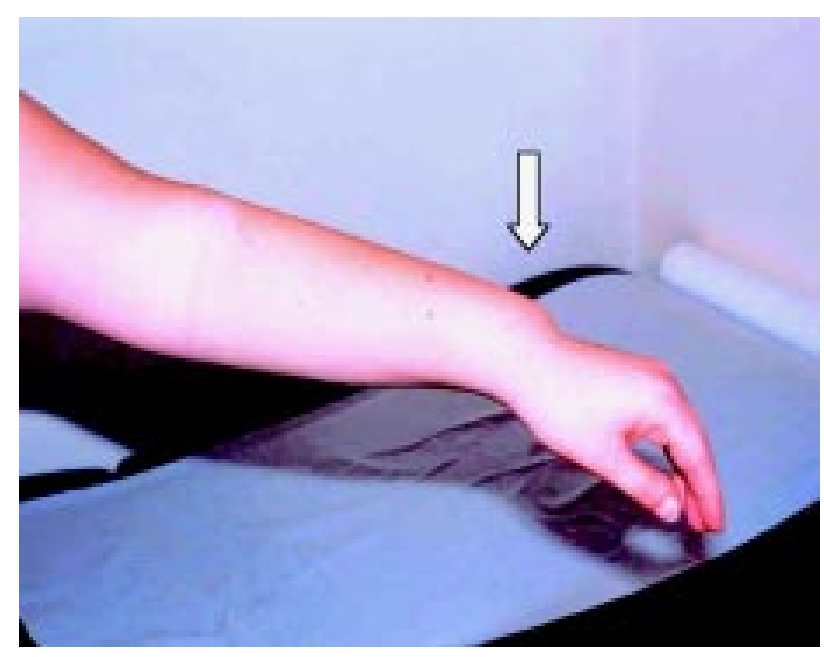

Figure 2. Clinical appearance of Madelung deformity (personal archive). 
pals/metatarsals with metaphyseal flaring, altered alignment at wrist or wedged wrist and triangularization of radial head. The Madelung deformity might not be clinically recognizable until mid-childhood and mainly in males and is usually preceded by radiological signs s $^{24,66,41}$ (Figure 3 ).

Clinical syndromes associated with SHOX deficiency are: Turner syndrome, Léri-Weill dyschondrosteosis, Langer mesomelic dysplasia, Idiopathic short stature.

\section{Turner syndrome (TS)}

Patients afflicted with Turner syndrome (one in 2500 live born females) are cytogenetically characterized by a complete or partial loss of one $\mathrm{X}$ chromosome. About $60 \%$ have a 45,XO karyotype and the rest are either mosaics $45, \mathrm{XO} / 46, \mathrm{XX}$ or have a variety of structural defects of the $\mathrm{X}$ chromosome. ${ }^{6,7}$ More than $90 \%$ of girls with Turner syndrome have short stature and SHOX represents the only related gene thus far recognized. ${ }^{1,2}$ It will thus be of great interest to determine which patients among mosaics will develop a less severe phenotype, with regard to short stature, depending upon the number of intact SHOX genes. ${ }^{42}$

Clement-Jones and colleagues ${ }^{15}$ suggested a possible involvement of SHOX-related growth impairment in the expression of other Turner stigmata such as high-arched palate, abnormal auricular development, cubitus valgus, genu valgum and short metacarpals. Other clinical investigators ${ }^{39,43,44}$ reported that SHOX haploinsufficiency could lead to additional Turner skeletal abnormalities such as mesomelia and Madelung deformity. Ogata et al. ${ }^{45,46}$ claimed
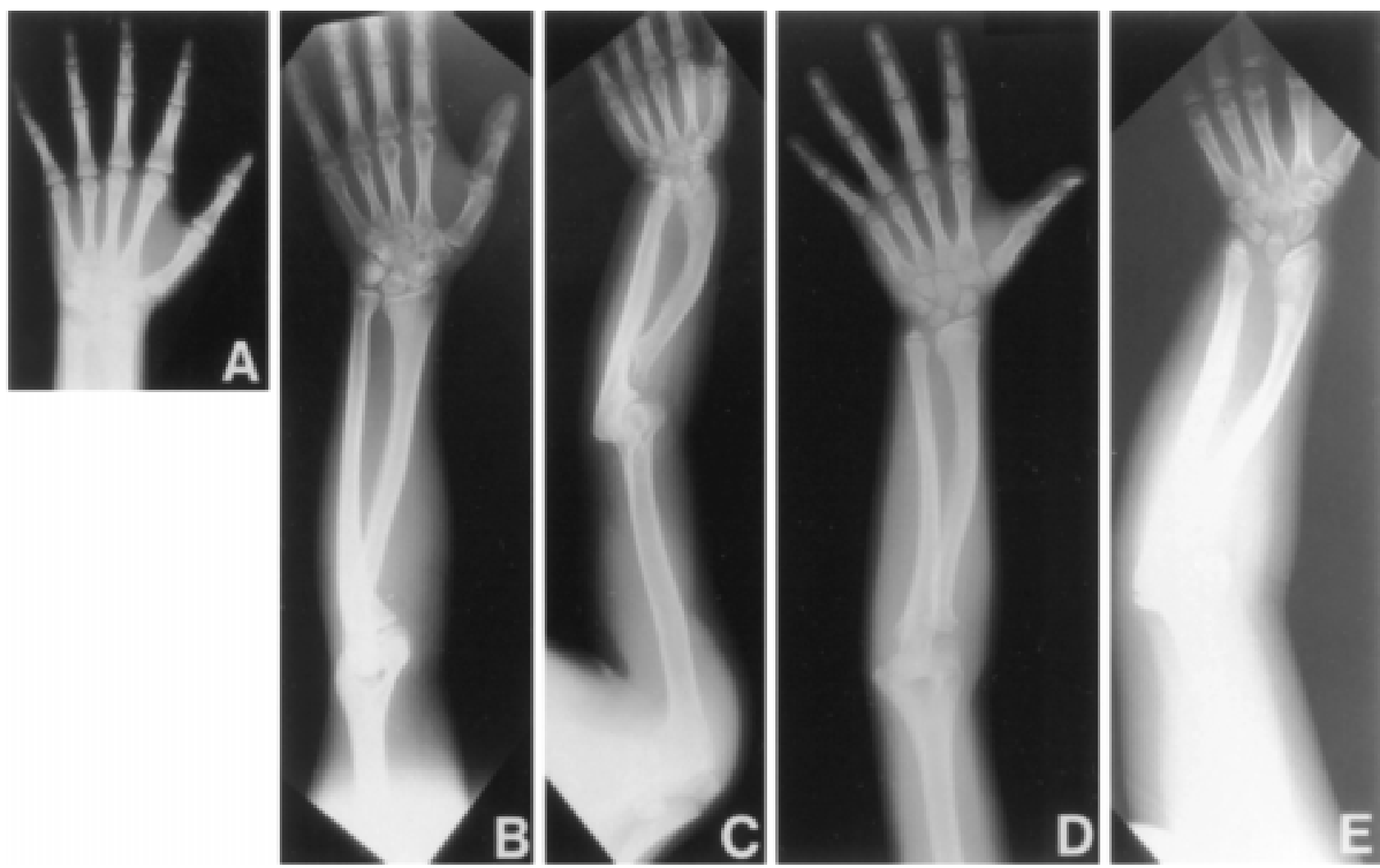

Figure 3. Radiological findings in SHOX deficiency. A. Borderline short $4^{\text {th }}$ metacarpal. B. Borderline short $4^{\text {th }}$ metacarpal, mildly decreased carpal angle, and slightly shortened and bowed radius. C. Short $4^{\text {th }}$ metacarpal, cubitus valgus, decreased carpal angle, angulation of the distal radius, and short and curved radius. D. Borderline short $4^{\text {th }}$ metacarpal, mild cubitus valgus, and deformation of the medial half of the distal radius. E. Short $4^{\text {th }}$ metacarpal, cubitus valgus, decreased carpal angle, angulation of the distal radius, and short and curved radius. ${ }^{43}$

Reprinted with permission from the Endocrine Society. 
that there must be additional factors such as an Xlinked "lymphogenic"gene, located between the Duchenne muscular dystrophy (DMD) and monoamine oxidase A (MAOA) genes that could also be responsible for the development of soft tissue and skeletal abnormalities in Turner syndrome.

\section{Léri-Weill dyschondrosteosis (LWD)}

LWD is the most common form of mesomelic skeletal dysplasia with an estimated prevalence of $1 / 2000$, Madelung deformity being a hallmark sign. As far as stature is concerned, final height in females is approximately $1.45 \mathrm{~m}$ and in males $1.55 \mathrm{~m}$. The phenotype is highly variable with some patients being of normal height and showing no clinical signs of Madelung deformity. ${ }^{28,31,43}$ There is also great variation among patients with identical mutations belonging to the same family. ${ }^{8,9,20}$ Females are more frequently affected than males and growth failure as well as clinical features, such as bilateral Madelung deformity, have been described as being more severe in females than in males..$^{31,43}$

Compared to their unaffected siblings, SHOX haploinsufficient females were 2.4 SDS $(14.4 \mathrm{~cm})$ shorter and SHOX haploinsufficient males 0.8 SDS $(5.3 \mathrm{~cm})$ shorter at final height, although females and males in the SHOX haploinsufficient cohort were both -2.14 SDS at birth and - 2.1 SDS through childhood. ${ }^{47}$ On the other hand, despite a relatively small number of LWD individuals with family data available, familial comparisons revealed that only females with LWD and a de novo SHOX mutation had a height SDS that was significantly different from their mid-parental height. According to these studies, there must exist a sex and age influence on SHOX haploinsufficiency, though pertinent data remain controversial. In a recent study among patients with LWD it was demonstrated that growth failure was observed during the first years of life with a mean height loss of 2.16 SDS in childhood, whereas pubertal growth was mildly or not affected. Furthermore, it was shown that children with a severe degree of wrist deformity were significantly shorter than those with mild deformities. ${ }^{31}$

Heterozygous mutations of the SHOX gene have been reported in patients with Léri-Weill dyschondrosteosis ${ }^{8,9,20,48}$ at an estimated prevalence ranging from $60 \%$ to $100 \%$. Among patients with Léri-Weill syndrome, SHOX defects up to $70 \%$ were SHOX gene deletions and $15 \%$ were point mutations. ${ }^{24}$ The absence of SHOX deficiency in almost $30 \%$ of patients with Léri-Weill syndrome may be explained by: 1) the presence of mutations in unanalyzed regions, such as the upstream, intragenic or downstream regulatory sequences of SHOX, ${ }^{37} 2$ ) the sexchromosome-specific regulation, 3) the involvement of modifying genes, or 4) the genetic heterogeneity. ${ }^{49}$ In table 1 the molecular and clinical studies on SHOX deficiency associated with LWD are summarized. The differences in percentages of detected SHOX haploinsufficiency in different studies could be explained by a variable ascertainment of populations studied.

\section{Langer mesomelic dysplasia (LMD)}

LMD is characterized by severe short stature (<-2SDS) with hypoplasia or aplasia of the ulna and fibula and has been described as the most severe type of LWD. ${ }^{50}$ All patients with this syndrome have homozygous deficiency of the SHOX gene. ${ }^{8,43}$ Fukami et al. ${ }^{37}$ summarized the clinical and molecular data on 17 patients with LMD reported so far. ${ }^{8,9,27,30,51-54}$ The patients had a mean height deficit of -6.18 SDS and presented various degrees of SHOX deficiency associated skeletal abnormalities. One third of the above studied patients resulted from homozygous deletions, one third from homozygous point mutations while the rest were not examined. It is interesting that a severe and atypical form of dyschondrosteosis has recently been reported in a mother and her son presenting features of Léri-Weill dyschondrosteosis in the upper extremities and of Langer Mesomelic Dysplasia in the lower extremities, attributed to a heterozygous deletion of the SHOX gene in both of them. ${ }^{55}$ These findings broaden the phenotypic spectrum associated with SHOX gene functional haploinsufficiency.

\section{Idiopathic short stature (ISS)}

Idiopathic short stature is characterized by significant short stature (<-2SDS), a persistently low growth rate for age and no biochemical or other evidence of a specific growth retarding condition. Hence, after excluding a long list of various causes of short stature, including chronic systemic disor- 
Table 1. Pertinent literature data on SHOX haploinsufficiency in Leri-Weill dyschondrosteosis

\begin{tabular}{|c|c|c|c|c|c|c|c|c|c|}
\hline \multirow[t]{3}{*}{ Study } & \multirow[t]{3}{*}{ Phenotype } & \multirow{3}{*}{$\begin{array}{c}\mathrm{N} \\
(\text { Fam or I) }\end{array}$} & \multirow{3}{*}{$\begin{array}{c}\text { No with } \\
\text { mut } \\
(\%)\end{array}$} & \multicolumn{4}{|c|}{ Height SDS } & \multirow{2}{*}{\multicolumn{2}{|c|}{$\begin{array}{c}\text { Morphologic } \\
\text { Stigmata } \%\end{array}$}} \\
\hline & & & & \multirow[t]{2}{*}{$\overline{\text { Birth }}$} & Childhood & \multicolumn{2}{|c|}{ Final $(\%)<2$ SD } & & \\
\hline & & & & & $\mathbf{M}$ & $\mathbf{F} \quad \mathbf{M}$ & & MD & $\begin{array}{c}\text { Mesomelic } \\
\text { dwarfism }\end{array}$ \\
\hline $\begin{array}{l}\text { Belin et al., } \\
1998^{9}\end{array}$ & $\begin{array}{l}\mathrm{Ht}<-2 \mathrm{SD} \text { and } \\
\mathrm{MD} \text { on X-ray }\end{array}$ & 8 (Fam) & 100 & NR & & & & NR & \\
\hline $\begin{array}{l}\text { Shears et al., } \\
1998^{8}\end{array}$ & DP short stature & 7 (Fam) & 100 & NR & & & & NR & \\
\hline $\begin{array}{l}\text { Kosho et al., } \\
1999^{43}\end{array}$ & $\begin{array}{l}\text { Partial or total } \\
\text { monosomy of PAR1 }\end{array}$ & $14(\mathrm{I})$ & 100 & -1.1 & $-2.44 \quad-2$ & $-2.9-2.0$ & (79) & 71 & 57 \\
\hline $\begin{array}{l}\text { Cormier-Daire }{ }^{49} \\
\text { et al., } 1999\end{array}$ & $\begin{array}{l}\mathrm{Ht}<-2 \mathrm{SDS} \text { and } \\
\mathrm{MD} \text { on X-ray }\end{array}$ & 8 (Fam) & 100 & NR & & & & 100 & \\
\hline $\begin{array}{l}\text { Schiller et al., } \\
2000^{20}\end{array}$ & $\mathrm{MD}$ & 18 (Fam) & 56 & & $-1.9-2.1$ & $-3.87-2.53$ & & NR & \\
\hline $\begin{array}{l}\text { Grigelioniene } \\
\text { et al., } 2000^{21}\end{array}$ & DP short stature & 5 (Fam) & 60 & NR & & & & NR & \\
\hline $\begin{array}{l}\text { Huber et al., } \\
2001^{23}\end{array}$ & $\begin{array}{l}\mathrm{Ht}<-2 \mathrm{SDS} \text { and } \\
\text { DP limbs }\end{array}$ & 16 (Fam) & 100 & NR & & & & 100 & \\
\hline & MD on X-ray & & & & & & & & \\
\hline $\begin{array}{l}\text { Ross et al., } \\
2001^{25}\end{array}$ & Short or MD & 21 (Fam) & 100 & & $-2.0-1.9$ & $-2.3-3.0$ & & 74 & \\
\hline $\begin{array}{l}\text { Falcinelli } \\
\text { et al., 2002 }\end{array}$ & $\begin{array}{l}\text { DP short stature } \\
\text { and MD on X-ray } \\
\text { NL karyotype }\end{array}$ & 21 (Fam) & 62 & NR & & & & 100 & 100 \\
\hline $\begin{array}{l}\text { Flanagan } \\
\text { et al., } 2002^{26}\end{array}$ & MD operated & $18(\mathrm{I})$ & 67 & NR & & & & 100 & \\
\hline $\begin{array}{l}\text { Munns et al., } \\
2003^{47}\end{array}$ & MD operated & 10 (Fam) & 100 & -0.89 & -2.00 .0 & $-2.1-2.0$ & $(54)$ & 73 & 92 \\
\hline $\begin{array}{l}\text { Binder et al., } \\
2004^{31}\end{array}$ & $\begin{array}{l}\text { MD and } \\
\text { DP limbs }\end{array}$ & 20 (Fam) & 82 & -0.59 & $-2.30-1.72$ & & & 100 & \\
\hline $\begin{array}{l}\text { Schneider } \\
\text { et al., } 2005^{35}\end{array}$ & $\begin{array}{l}\text { DP short stature and } \\
\text { MD }\end{array}$ & 118 (I) & 34 & NR & & & & NR & \\
\hline $\begin{array}{l}\text { Ross et al., } \\
2005^{71}\end{array}$ & $\begin{array}{l}\text { Prepubertal } \\
\text { children }\end{array}$ & $34(\mathrm{I})$ & 100 & & $-2.3-1.853$ & & & & \\
\hline
\end{tabular}

Fam: families; I: individuals; NR: not reported; Ht: height; NL: normal; MD: Madelung deformity; DP: disproportionate; mut: mutations; F: females; M: males

ders, skeletal, endocrine and chromosomal abnormalities, one is left with the diagnosis of idiopathic short stature (ISS). Unexplained short stature poses a dilemma for health professionals who diagnose and treat growth disorders. Less than $1 \%$ of children under the $3^{\text {rd }}$ percentile for height will be found to be growth hormone deficient or have mutations involving growth hormone releasing hormone (GHRH), GH, IGF-1 genes or their respective re- ceptors. ${ }^{25}$ It is, therefore, of great interest that SHOX gene mutations may explain growth failure in a proportion, albeit small, of children with ISS. In Table 2 studies on gene SHOX haploinsufficiency in children with ISS are summarized. In the majority of pertinent studies, SHOX gene deletions or mutations have been detected in about $2 \%$ of children with ISS and this prevalence would imply a population prevalence of at least 1 in 2000 children. Clas- 
Table 2. Summary of studies on SHOX haploinsufficiency in ISS

\begin{tabular}{|c|c|c|c|}
\hline Study & Phenotype & $\begin{array}{c}\text { Patients } \\
\text { N }\end{array}$ & $\begin{array}{c}\text { Mutations } \\
(\%)\end{array}$ \\
\hline $\begin{array}{l}\text { Rao et al., } \\
1997^{1}\end{array}$ & $\begin{array}{l}\mathrm{Ht}<-2 \text { SDS and } \\
\text { NL karyotype and } \\
\text { NL X-rays }\end{array}$ & 91 & 1.1 \\
\hline $\begin{array}{l}\text { Binder et al., } \\
2000^{67}\end{array}$ & $\begin{array}{l}\mathrm{Ht}<-2 \mathrm{SDS} \text { and } \\
\mathrm{NL} \mathrm{X} \text {-rays }\end{array}$ & 68 & 1.5 \\
\hline $\begin{array}{l}\text { Musebeck } \\
\text { et al., 2001 }\end{array}$ & $\begin{array}{l}\mathrm{Ht}<-2 \mathrm{SDS} \text { and } \\
\mathrm{NL} \text { family } \mathrm{Ht} \text { and } \\
\text { NL X-rays }\end{array}$ & 35 & - \\
\hline $\begin{array}{l}\text { Rappold } \\
\text { et al., } 2002^{28}\end{array}$ & $\mathrm{Ht}<-2 \mathrm{SDS}$ & 900 & 2.4 \\
\hline $\begin{array}{l}\text { Ezquieta } \\
\text { et al., } 2002^{42}\end{array}$ & Short stature & 73 & - \\
\hline $\begin{array}{l}\text { Stuppia } \\
\text { et al., } 2003^{73}\end{array}$ & $\begin{array}{l}\mathrm{Ht}<-2 \text { SDS and } \\
\text { NL karyotype and } \\
\text { NL X-rays }\end{array}$ & 56 & 12.4 \\
\hline $\begin{array}{l}\text { Binder } \\
\text { et al., } 2003^{32}\end{array}$ & $\begin{array}{l}\mathrm{Ht}<-2 \mathrm{SDS} \text { and } \\
\text { NL karyotype }\end{array}$ & 140 & 2 \\
\hline $\begin{array}{l}\text { Schneider } \\
\text { et al., } 2005^{35}\end{array}$ & $\mathrm{Ht}<-\mathrm{SDS}$ & $>1500$ & 2 \\
\hline
\end{tabular}

Ht: height; NL: normal; ISS: idiopathic short stature

sic GH deficiency is estimated to be present in 1 out of 3500 children and Turner syndrome in 1 in 2500 girls. ${ }^{25-28}$

Thus, the prevalence of short stature due to SHOX gene deletion among children with ISS appears to be analogous to or even more frequent than that of GH deficiency or Turner syndrome. ${ }^{28}$ According to Munns et al., ${ }^{47}$ a candidate for SHOX deficiency investigation is the child with low birth height (but within the lower limits), stature during childhood near the lower limits (between -2.2 and -2.1 SDS for females and males, respectively) or final height well below the lower normal limits (between -2.84 and -2.36 SDS for females and males, respectively) and family history of short stature in at least one parent.

\section{GENOTYPE-PHENOTYPE CORRELATIONS}

SHOX deficiency appears to be a major cause of growth failure in $100 \%$ of patients with Turner or Langer syndrome, approximately $70 \%$ in Léri-Weill syndrome and about $2 \%$ in patients previously di- agnosed as having "idiopathic" short stature.

Taken together, the data of some recent studies $^{22,25,31}$ indicate that the growth deficit caused by SHOX defects in patients with Léri-Weill dyschondrosteosis is approximately 2SDS, which is not as severe as that encountered in other osteodysplasias or in Turner syndrome. This observation suggests that there may be other genes - such as the lymphogenic gene(s) mapped to a $\sim 9 \mathrm{Mb}$ region between DMD and MAOA loci on Xp chromosome-that are responsible for the impaired development of soft tissue, visceral and skeletal abnormalities and shortness. ${ }^{45,46}$

The different prevalence of Madelung deformity between LWD and Turner syndrome ( $75 \%$ vs. $\sim 8 \%$ ) has been attributed to loss of other X-linked, non-pseudoautosomal growth genes which masks the full phenotype of SHOX haploinsufficiency in Turner syndrome. This hypothesis however has to be proven. The modifying gene(s) could be on an autosome or on the X chromosome itself. ${ }^{8}$ An alternative explanation may be that girls with Turner syndrome are protected from developing Madelung deformity by their sex steroid deficiency, which does not occur in females with LWD. However, the deformity does not seem to develop even in females with Turner syndrome treated with estrogens before epiphyseal closure. Nevertheless, therapy even in these cases usually starts in the late teens and at a low dose. ${ }^{25}$ Unfortunately, there is no mouse or murine model for SHOX haploinsufficiency. Thus, humans represent the only prototype for studying the role of SHOX gene in normal and abnormal growth and development.

The role of estrogens, being the sole known factor influencing the phenotype in SHOX haploinsufficiency, remains controversial. In both sexes, skeletal maturation is advanced by estrogens and serum estrogen concentration is higher and begins to increase at a younger age in females. ${ }^{56} \mathrm{SHOX}$ appears to function as a repressor for growth plate fusion and skeletal maturation in the distal limb region, so that SHOX haploinsufficiency results in unbalanced, premature growth plate fusion and advanced skeletal maturation. It has been suggested by some studies $^{39,40,43,44,57}$ that the estrogenic effect could account 
for the observation that females are more severely affected than males and skeletal features tend to worsen with age. On the other hand, Ross et al., ${ }^{25}$ as well as Binder et al., ${ }^{31}$ have made the following observations. 1) In LWD cohorts, males are just as short as females and they may go unrecognized, being diagnosed in childhood at least in part as ISS. In such cases family history could provide a clue to the diagnosis because most of the SHOX abnormalities observed in males are familial. 2) Growth failure occurs during the first years of life, whereas pubertal growth may be mildly or not affected. 3) Estrogens may have an impact on the severity of the Madelung deformity, but its antecedents are present very early in childhood both in males and females.

Two identical point mutations, c. $674 \mathrm{C}>\mathrm{T}^{1,9,15,22,25,26}$ and c.599G $>$ C [RR Project HD, GDFN HD, www.shox.uni-hd.de], have been described in patients with either ISS or LWD. This finding suggests that SHOX haploinsufficiency can lead to different clinical phenotypes. Deletions of the SHOX gene have been described as being far more frequent than point mutations among patients with LWD, but neither the size of the deletion nor the type of point mutation are correlated with the severity of the phenotype. ${ }^{8}$ This phenomenon is known as phenotypic heterogeneity and could be attributed to background genetic effects, environmental factors and chance events. This is commonly observed in haploinsufficiency syndromes, when the loss of action of the one allele results in a $50 \%$ reduction of overall activity. ${ }^{58}$ Because the underlying principle in haploinsufficiency syndromes is the disturbance of a delicately balanced temporal and spatial expression, variations in the expression level of the remaining (intact) SHOX gene copy could help explain the variable phenotypic expression of SHOX mutations. Another possible explanation for the phenotypic heterogeneity of SHOX mutations might reside in the biochemical properties of the SHOX-encoded protein. Similar phenotypic heterogeneities have been described for other "transcription factor disorders" and might be attributed to their role as master regulatory switches within one or several developmental pathways. Recent examples are PIT1 defects leading to multiple hormone defects, ${ }^{59}$ as well as mutations within the gene encoding for the transcrip- tion factor GLI3 that have been demonstrated to cause three different clinical conditions, namely the Greig cephalopolysyndactily syndrome, ${ }^{60}$ the Pallister-Hall syndrome ${ }^{61}$ and postaxial polydactyly type A. ${ }^{62}$ In all these examples, the clinically observed phenotype is strongly dependent on the position of the mutated molecule within the specific developmental pathway. ${ }^{63}$

\section{TREATMENT PERSPECTIVES}

The presence of one or more skeletal abnormalities, known to occur in dyschondrosteosis or Turner phenotypes, should prompt the analysis for SHOX gene deletions or mutations in children and adults with short stature. It has now been well established that a thorough clinical investigation is a crucial first step in selecting patients with a likely defect in the SHOX gene. For this purpose, detailed evaluation of the $\mathrm{x}$-rays of forearms and lower limbs for subtle radiographic changes should be carried out.

In general, the clinician should consider SHOX deficiency in any patient with: a) "idiopathic" short stature and especially a stature lower than expected from parental height, b) "familial short stature", especially if there is a female predominance in the family, and c) disproportionate growth of the forearms or lower legs. ${ }^{24}$

For SHOX haploinsufficiency, two therapeutic interventions can be considered. Since growth hormone (rhGH) therapy improves the growth pattern in Turner syndrome, despite the absence of GH deficiency, ${ }^{64,65}$ it may also be advantageous in patients with SHOX haploinsufficiency. Another form of intervention could be the use of gonadotrophin releasing hormone analogue (GnRHa), which can suppress gonadal steroid production and may serve to mitigate the development of skeletal features and prolong the period of growth. ${ }^{39}$

To date, there have been five reports of rhGH therapy in individuals with SHOX haploinsufficiency. Table 3 summarizes the published data in patients with SHOX haploinsufficiency treated with rhGH. ${ }^{42,66-69}$ The data are not complete in all cases and there was a wide range of rhGH dose. No ad- 
Table 3. Cumulative growth data from published studies on rhGH therapy in patients with SHOX haploinsufficiency

\begin{tabular}{|c|c|c|c|c|c|c|c|c|c|}
\hline \multirow[t]{2}{*}{ Study } & \multirow[t]{2}{*}{$\begin{array}{l}\text { Number of } \\
\text { patients }\end{array}$} & \multirow[t]{2}{*}{$\begin{array}{l}\text { rhGH dose } \\
(\mathrm{IU} / \mathrm{Kg} / \mathrm{wk})\end{array}$} & \multicolumn{4}{|c|}{$\begin{array}{c}\text { Ht SDS } \\
\text { (at months of therapy) }\end{array}$} & \multicolumn{3}{|c|}{$\begin{array}{c}\text { HV SDS } \\
\text { (at months of therapy) }\end{array}$} \\
\hline & & & $\mathbf{0}$ & 12 & 24 & 36 & $\mathbf{0}$ & 12 & 24 \\
\hline Shanske et al., $1999^{66}$ & 1 & NR & -4.3 & -3.3 & & & -3.3 & 6.0 & NR \\
\hline \multirow[t]{2}{*}{ Binder et al., $2000^{67}$} & 1 & 1 & -3.5 & -2.5 & & & -2.3 & 3.9 & NR \\
\hline & 2 & 1 & -2.5 & -1.6 & & & -2.0 & 5.4 & NR \\
\hline \multirow[t]{3}{*}{ Ogata et al., 2001c $\mathrm{c}^{68}$} & 1 & 0.5 & -3.9 & -2.8 & & & -2.5 & 6.4 & NR \\
\hline & 2 & 0.5 & NR & NR & & & -3.0 & 1.4 & 0.9 \\
\hline & 3 & 0.5 & -4.0 & -4.0 & -4.0 & & NR & NR & NR \\
\hline Ezquieta et al., $2002^{42}$ & 1 & NR & $-2,9$ & NR & & -1.7 & NR & NR & NR \\
\hline \multirow[t]{2}{*}{ Munns, Berry et al., $2003^{69}$} & 1 & 0.6 & -3.0 & -2.8 & -2.7 & & -2.5 & 2.7 & 2.9 \\
\hline & 2 & 0.8 & -3.0 & -2.2 & -1.9 & & 0.5 & 8.2 & 4.3 \\
\hline Mean data & & 0.7 & -3.5 & -2.7 & -2.9 & & -2.2 & 4.9 & 2.7 \\
\hline \multicolumn{3}{|l|}{ Change from start of therapy } & & 0.8 & 0.6 & 1.2 & & 7.1 & 4.9 \\
\hline
\end{tabular}

\{Studies that analyzed the effect of rhGH in patients with clinical LWD for whom SHOX mutation analysis was not available are not included $\left.{ }^{74-76}\right\}$. Ht: height; HV: height velocity; NR: not reported

verse effects of rhGH therapy were observed. Age appropriate advancement of bone age was seen, indicating that any height advancement from rhGH therapy may result in an improvement in final height. There was only minimal radiological progression and no clinical worsening of Madelung deformity in all patients. All patients (apart from patient 3 of Ogata et al. $)^{68}$ demonstrated short-term benefit from rhGH therapy, with a mean improvement in height SDS of 0.8 at 12 months $(n=8)$ and 0.6 at 24 months $(n=3)$. These data suggest that the effect of $r G H$ may diminish after the first 12 months of therapy, a finding also seen in other skeletal dysplasias. ${ }^{64,70}$ The overall data suggest that the higher doses of rhGH were associated with greater short-term benefit. As there are no LWD-specific growth charts to be used for the assessment of the therapeutic response to $\mathrm{rhGH}$, it is important to note that the height of females with SHOX haploinsufficiency has been demonstrated to be reduced by approximately 0.7 SDS from childhood to final height. ${ }^{20,25,43}$ Taking this into consideration, the maintenance of the same height SDS through this period may constitute evidence of growth improvement. ${ }^{69}$ However, the number of reported patients with SHOX haploinsufficiency treated with rhGH is small and further studies are required before definitive conclusions can be drawn.

\section{CONCLUSION}

The elucidation of the respective developmental pathway of the SHOX gene and the determination of its exact position therein constitute a prerequisite for a full understanding of the variable phenotypic consequences of SHOX mutations. Understanding SHOX as part of a genetic program responsible for normal growth and bone development will also allow the identification of additional factors within this program that might modify the effects of the functional haploinsufficiency of the SHOX gene. Along these lines, SHOX might turn out to represent another example of a gene implicated in several clinical conditions formerly regarded as distinct syndromes. It is possible that SHOX haploinsufficiency is responsible not only for the ISS or the LWD but also for intermediate mild skeletal dysplasias. ${ }^{63}$ Taken together, the biochemical characterization of the SHOX-encoded transcription factor, the identification of upstream ${ }^{37}$ and downstream ${ }^{36}$ regulators or targets of the SHOX gene and its positioning within a specific developmental pathway are priority objectives. At present, the exact action of SHOX protein cannot be defined. ${ }^{17,34}$ Functional studies will improve our understanding of the role of the SHOX gene in skeletal and cartilage growth. 


\section{REFERENCES}

1. Rao E, Weiss B, Fukami M, et al, 1997 Pseudoautosomal deletions encompassing a novel homeobox gene cause growth failure in idiopathic short stature and Turner syndrome. Nature Genet 16: 54-63.

2. Ellison JW, Wardak Z, Young MF, Gehron Robey P, Laig-Webster M, Chiong W, 1997 PHOG, a candidate gene for involvement in the short stature of Turner syndrome. Hum Mol Genet 6: 1341-134.

3. Ballabio A, Bardoni B, Carrozzo R, et al, 1989 Contiguous gene syndrome due to deletions in the distal short arm of the human X chromosome. Proc Nat Acad Sci USA 86: 10001-10005.

4. Ogata T, Goodfellow P, Petit C, Aya M, Matsuo N, 1992 Short stature in a girl with a terminal Xp deletion distal to DXYS15: localization of a growth gene(s) in the pseudoautosomal region. J Med Genet 29: 455-459.

5. Ogata T, Matsuo N, 1993 Sex chromosome aberrations and stature: deduction of the principal factors involved in the determination of adult height. Hum Genet 91: 551-562.

6. Ogata T, Yoshizawa A, Muroya K, Matsuo N, Fukushima Y, Rappold G, Yokoya S, 1995 Short stature in a girl with partial monosomy of the pseudoautosomal region distal to DXYS15: further evidence for the assignment of the critical region for a pseudoautosomal growth gene(s). J Med Genet 32: 831-834.

7. Ogata N, Matsuo T, 1995 Turner syndrome and female sex chromosome aberrations: deduction of the principal factors involved in the development of clinical features. Hum Genet 95: 607-629.

8. Shears DJ, Vassal HJ, Goodman FR, et al, $1998 \mathrm{Mu}-$ tation and deletion of the pseudoautosomal gene SHOX cause Léri-Weill dyschondrosteosis. Nat Genet 19: 70-73.

9. Belin V, 1998 SHOX mutations in dyschondrosteosis (Léri-Weill syndrome). Nat Genet 19: 67-69.

10. Gehring WJ, Affolter M, Burglin T, 1994 Homeodomain proteins. Annu Rev Biochem 63: 487-526.

11. Boncinelli E, 1997 Homeobox genes and disease. Curr Opin Genet Dev 7: 331-337.

12. Baldwin CT, Hoth CF, Amos JA, da-Silva EO, Milunsky A, 1992 An exonic mutation in the HuP2 paired domain gene causes Waardenburg's syndrome. Nature 355: 637-638.

13. Glaser T, Walton DS, Maas RL, 1992 Genomic structure, evolutionary conservation and aniridia mutations in the human PAX6 gene. Nat Genet 2: 232-239.

14. Muragaki Y, Mundlos S, Upton J, Olson BJ, 1996 Altered growth and branching patterns in synpolydactyly caused by mutations in HOXD. Science 272: 548-551.

15. Clement-Jones M, Schiller S, Rao E, et al, 2000 The short stature homeobox gene SHOX is involved in skeletal abnormalities in Turner syndrome. Hum Mol Genet 9: 695-702.
16. Rosenfeld R, 2001 Editorial: A SHOX to the system. J Clin Endocrinol Metab 86: 5672-5673.

17. Munns C, Haase H, Crowther L, et al, 2004 Expression of SHOX in human fetal and childhood growth plate. J Clin Endocrinol Metab 89: 4130-4135.

18. Marchini A, Martilla T, Winter A, et al, 2004 The short stature homeobox protein SHOX induces cellular growth arrest and apoptosis and is expressed in human growth plate chondrocytes. J Biol Chem 279: 37103-37114.

19. Rappold GA, 1993 The pseudoautosomal regions of the human sex chromosomes. Hum Genet 92: 315-324.

20. Schiller S, Spranger S, Schechinger B, et al, 2000 Phenotypic variation and genetic heterogeneity in LériWeill syndrome. Eur J Hum Genet 8: 54-62.

21. Grigelioniene G, Eklof O, Ivarson SA, et al, 2000 Mutations in short stature homeobox containing gene (SHOX) in dyschondrosteosis but not in hypochondroplasia. Hum Genet 107: 145-149.

22. Grigelioniene G, Schoumans J, Neumeyer L, et al, 2001 Analysis of short stature homeobox-containing gene (SHOX) and auxological phenotype in dyschondrosteosis and isolated Madelung deformity. Hum Genet 109: 551-558.

23. Huber C, Cusin V, Le Merrer M, et al, 2001 SHOX point mutations in dyschondrosteosis. J Med Genet 38: 323-351.

24. Huber C, Cormier-Daire V, 2004 Genetics and the SHOX gene. Arch Pédiatrie 11: 555-556.

25. Ross J, Scott C, Martulla P, et al, 2001 Phenotypes associated with SHOX deficiency. J Clin Endocrinol Metab 86: 5674-5680.

26. Flanagan SF, Munns CF, Hayes M, et al, 2002 Prevalence of mutations in the short stature homeobox containing gene (SHOX) in Madelung deformity of childhood. J Med Genet 39: 758-763.

27. Zinn AR, Wei F, Zhang L, et al, 2002 Complete SHOX deficiency causes Langer mesomelic dysplasia. Am J Med Genet 110: 158-163.

28. Rappold G, Fukami M, Niesler B, et al, 2002 Deletions of the homeobox gene SHOX (short stature homeobox) are an important cause of growth failure in children with short stature. J Clin Endocrinol Metab 87: 1402-1406.

29. Falcinelli C, Lughetti L, Percdesepe A, et al, 2002 SHOX point mutations and deletions in Léri-Weill dyschondrosteosis. J Med Genet 39: E33

30. Shears DJ, Guillen-Navarro E, Sempere-Miralles M, Domingo-Jimenez R, Scambler PJ, Winter RM, 2002 Pseudoautosomal inheritance of Langer mesomelic dysplasia caused by a SHOX homeobox missence mutation. Am J Med Genet 110: 153-157.

31. Binder G, Renz A, Martinez A, et al, 2004 SHOX haploinsufficiency and Léri-Weill dyschondrosteosis: Prevelence and growth failure in relation to mutation, sex, and degree of wrist deformity. J Clin Endocrinol Metab 
89: 4403-4408.

32. Binder G, Ranke M, Martin D, 2003 Auxology is a valuable instrument for the clinical diagnosis of SHOX haploinsufficiency in school-age children with unexplained short stature. J Clin Endocrinol Metab 88: 4891-4896.

33. Lien S, Szyda J, Schenchinger B, Rappold G, Arnheim N, 2000 Evidence for heterogeneity in recombination in the human pseudoautosomal region: high resolution analysis by sperm typing and radiation-hybrid mapping. Am J Hum Genet 66: 557-566.

34. Schneider K, Marchini A, Sabherwal N, et al, 2005 Alteration of DNA binding, dimerization, and nuclear translocation of SHOX homeodomain mutations identified in Idiopathic Short Stature and Léri-Weill Dyschondrosteosis. Hum Mutat 26: 44-52.

35. Schneider KU, Sabherwal N, Jantz K, et al, 2005 Identification of a major recombination hotspot in patients with short stature and SHOX deficiency. Am J Hum Genet 77: 89-96.

36. Benito-Sanz S, Thomas NS, Huber C, et al, 2005 A novel class of Pseudoautosomal Region 1 deletions downstream of SHOX is associated with Léri-Weill dyschondrosteosis. Am J Hum Genet 77: 533-544.

37. Fukami M, Okuyama T, Yamamori S, Nishimura G, Ogata T, 2005 Microdeletion in the SHOX 3' region associated with skeletal phenotypes of Langer Mesomelic dysplasia in a 45,X/46,X,r(X) infant and LériWeill dyschondrosteosis in her 46,XX mother: implication for the SHOX enhancer. Am J Med Genet A 137: 72-76.

38. Hintz R, 2002 SHOX mutations. Rev Endocr Metab Disord 3: 363-367.

39. Ogata T, Matsuo N, Nishimura G, 2001a SHOX haploinsufficiency and overdose: impact of gonadal function status. J Med Genet 38: 1-6.

40. Fukami M, Nishi Y, Hasegawa Y, et al, 2004 Statural growth in 31 Japanese patients with SHOX haploinsufficiency: support for a disadvantageous effect of gonadal estrogens. Endocr J 51: 197-200.

41. Vickers D, 1998 Madelung's deformity. In: Cooney W, Linceid R, Dobyns J (eds) The wrist: diagnosis and operative treatment. St Louis, Mosby.

42. Ezquieta B, Cueva E, Oliver A, Gracia R, 2002 SHOX intragenic microsatellite analysis in patients with short stature. J Ped Endocrinol Metabol 15: 139-148.

43. Kosho T, Muroya K, Nagai et al, 1999 Skeletal features and growth patterns in 14 patients with haploinsufficiency of SHOX: Implications for the development of Turner syndrome. J Clin Endocrinol Metab 84: 46134621.

44. Ogata T, 2002a SHOX haploinsufficiency: lessons from clinical studies. Curr Opin Endoctinol Diabetes 9: 1320.

45. Ogata T, Muroya K, Matsuo N, et al, 2001b Turner syndrome and $\mathrm{Xp}$ deletions: Clinical and molecular studies in 47 patients. J Clin Endocrinol Metab 86: 5498-5508.

46. Ogata T, 2002b SHOX haploinsufficiency and its modifying factors. J Pediatr Endocrinol Metabol 15: 12891294.

47. Munns C, Glass I, Flanagan S, et al, 2003 Familial growth and skeletal features associated with SHOX haploinsufficiency. J Pediatr Endocrinol Metab 16: 987-996.

48. Cormier-Daire V, Huber C, Munnich A, 2001 Allelic and non-allelic heterogeneity in dyschondrosteosis (Léri-Weill syndrome). Am J Med Genet 106: 272-274.

49. Cormier-Daire V, Belin V, Cusin V, et al, 1999 SHOX gene mutations and deletions in dyschondrosteosis or Léri-Weill syndrome. Acta Paediatr Suppl 88: 55-59.

50. Kunze J, Klemm T, 1980 Mesomelic dysplasia, type Langer - homozygous state for dyschondrosteosis. Eur J Paediatr 134: 269-272.

51. Robertson SP, Shears DJ, Oei P, et al, 2000 Homozygous deletion of SHOX in a mentally retarded male with Langer mesomelic dysplasia. J Med Genet 37: 959964.

52. Ogata T, Muroya K, Sasaki G, Nishimura G, Kitoh H, Hattori T, 2002c SHOX nullizygocity and haploinsufficiency in a Japanese family: Implication for the development of Turner skeletal features. J Clin Endocrinol Metab 87: 1390-1394.

53. Thomas NS, Maloney V, Bass P, Mulik V, Wellesley D, Castle B, 2004 SHOX mutations in a family and a fetus with Langer mesomelic dwarfism. Am J Med Genet A 128: 179-184

54. Sabherwal N, Blaschke RJ, Marchini A, et al, 2004 A novel point mutation A170P in the SHOX defines impaired nuclear translocation as a molecular cause for Léri-Weill dyschondrosteosis and Langer dysplasia. J Med Genet 41: e 83.

55. Bieganski T, Bik K, Cormier-Daire V, Huber C, Nowicki G, Kozlowski K, 2005 Severe, atypical form of dyschondrosteosis (report of two cases). Eur J Pediatr 164: 539-543.

56. MacGillivray MH, Morishima A, Conte F, Grumbach M, Smith EP, 1998 Pediatric endocrinology update: an overview. The essential roles of estrogens in pubertal growth, epiphyseal fusion and bone turnover: lessons from mutations in the genes for aromatase and the estrogen receptor. Horm Res 49: Suppl 1: 2-8.

57. Fukami M, Matsuo N, Hasegawa T, Sato S, Ogata T, 2003 Longitudinal auxological study in a female with SHOX haploinsufficiency and normal ovarian function. Eur J Endocrinol 149: 337-341.

58. Fisher E, Scambler PJ, 1994 Human haploinsufficiency - one for sorrow two for joy. Nat Genet 7: 5-9.

59. Watkins-Chow DE, Camper SA, 1998 How many homeobox genes does it take to make a pituitary gland? Trends Genet 14: 284-290.

60. Wild A, Kalff-Suske M, Vortkamp A, Bornholdt D, 
Konig R, Grzeschik KH, 1997 Point mutations in human GLI3 cause Greig syndrome. Hum Mol Genet 6: 1979-1984.

61. Kang S, Graham JM, Olney AH, Biesecker LG, 1997 GLI3 frame shift mutations cause autosomal dominant Pallister-Hall syndrome. Nat Genet 15: 266-268.

62. Radhakrishna U, Wild A, Grzeschik K, Antonarakis S, 1997 Mutation in GL3I in postaxial polydactyly type A. Nat Genet 17: 269-271.

63. Blashke J, Rappold G, 2000 SHOX: Growth, Léri-Weill and Turner Syndromes. TEM 11: 227-230.

64. Sas T, de Muinick Keizer-Schrama S, Stijnen T, et al, 1999 Normalization of height in girls with Turner syndrome after long-term growth hormone treatment: results of a randomized dose-response trial. J Clin Endocrinol Metab 84: 4607-4612.

65. Betts PR, Butler GE, Donaldson MDC, et al, 1999 A decade of growth hormone treatment in girls with Turner syndrome in the UK. Arch Dis Child 82: 34-39.

66. Shanske A, Ellison J, Vuguin P, et al, 1999 Deletion of the pseudoautosomal region in a male with a unique Y;13 translocation and short stature. Am J Med Genet 82: 34-39.

67. Binder G, Schwarze C, Ranke M, 2000 Identification of short stature caused by SHOX defects and therapeutic effect of recombinant human growth hormone. J Clin Endocrinol Metab 85: 245-249.

68. Ogata T, Onigata K, Hotsubo T, Matsuo N, Rappold G, 2001c Growth hormone and gonadotropin-releasing hormone analog therapy in haploinsufficiency of SHOX. Endocr J 48: 317-322.
69. Munns C, Berry M, Vickers D, et al, 2003 Effect of 24 months of recombinant growth hormone on height and body proportions in SHOX haploinsufficiency. J Pediatr Endocrinol Metab 16: 997-1004.

70. Kanaka-Gantenbein C, 2001 Present status of the use of growth hormone in short children with bone diseases (diseases of the skeleton). J Pediatr Endocrinol Metab 14: 17-26.

71. Ross JL, Kowal K, Quigley CA, et al, 2005 The phenotype of short stature homeobox gene (SHOX) deficiency in childhood: contrasting children with Léri-Weill dyschondrostosis and Turner syndrome. J Pediatr 147: 499-507.

72. Musebeck J, Mohnike K, Beye P, et al, 2001 Short stature homeobox-containing gene deletion screening by fluorescence in situ hybridization in patients with short stature. Eur J Pediatr 160: 561-565.

73. Stuppia L, Calabrese G, Gatta V, et al, 2003 SHOX mutations detected by FISH and direct sequencing in patients with short stature. J Med Genet 40: E11.

74. Hagnenas L 1994 Bone dysplasias and growth hormone treatment. In: Ranke MB, Gunnarsson R (eds) Progress in Growth Hormone Therapy. Five years of KIGS, J\&J Verlag, Mannheim; pp, 256-266.

75. Burren CP, Wertheer GA, 1996 Skeletal dysplasias: response to growth hormone therapy. J Pediatr Endocrionol Metab 9: 31-40.

76. Thuestad IJ, Ivarsson SA, Nilsoon KO, Wattsgard C, 1996 Growth hormone treatment in Léri-Weill syndrome. J Pediatr Endocrinol Metab 9: 201-204. 